\title{
International publication trends and collaboration performance of China in healthcare science and services research
}

\author{
Kai Chen ${ }^{1 \dagger}$, Qiang Yao ${ }^{2 * \dagger}$, Ju Sun², Zhi-fei He ${ }^{1}$, Lan Yao ${ }^{1}$ and Zhi-yong Liu ${ }^{1}$
}

\begin{abstract}
Background: In recent years, China's healthcare reforms and related studies have drawn particular global attention. The main objective of this study is to evaluate quantitatively the publication trends and collaboration performance of China in healthcare science and services (HSS) research.

Methods: Scientometric methods and visualization technology were used to survey the growth and development trends of HSS research based on the Web of Science publications during the past 15 years.

Results: China's international publications on HSS research increased rapidly compared to those of the global HSS and Chinese scientific studies. Growth trends indicate that collaboration among countries, institutions and authors has also increased. China's leading partners were all developed countries, such as the US, the UK, Australia and Canada, which have contributed to the majority of the joint publications. The academic impact of publications involving partners from European and American countries was relatively higher than those involving partners from Asian countries. Prominent institutions were universities that could be primarily classified into two groups, namely, Mainland China on the one hand and Hong Kong universities and foreign universities on the other. The most prominent actors were elite institutions, such as Peking University, Fudan University, Chinese University of Hong Kong, University of Hong Kong. The papers published by the Chinese Ministry of Health had relatively high academic impact, whereas those published by Mainland China universities alone had a lower academic impact compared to foreign cooperation papers. Issues related to the Chinese healthcare reform, priority diseases (e.g., breast cancer, HIV/AIDS, tuberculosis, etc.), health systems performance, quality of life and measurement tools, aging problems and research methods have been the most popular HSS topics in China in recent years.
\end{abstract}

Conclusions: Despite the extensive achievement of the Chinese HSS reforms and research, gaps and challenges remain to be addressed, including those related to health insurance and the effects of the evaluation of essential medicine systems, human resources training and allocation in the health sector, government hospitals reforms and health services systems remodeling. These findings could help scholars and decision-makers understand the current status and likely future trends of the Chinese HSS research, and help them select the most appropriate collaboration partners and policies.

Keywords: Healthcare science and services, China, Publication trends, Collaboration patterns, Research topics, Web of Science

\footnotetext{
* Correspondence: yaoqianghero@126.com

${ }^{\dagger}$ Equal contributors

${ }^{2}$ School of Political Science and Public Administration, Wuhan University,

Wuhan, Hubei 430072, People's Republic of China

Full list of author information is available at the end of the article
} 


\section{Background}

China has enjoyed rapid economic development since the reform and open policy implementation in 1978. Accordingly, China's economic reforms have achieved significant success. However, the Chinese healthcare system began to regress in the 1980 s, and many problems have been encountered thereafter. For example, from 1978 to 2012, China's GDP increased at a $17.7 \%$ compounded annual growth rate, whereas its total healthcare expenditure grew at a somewhat lower $15.7 \%$ compounded annual growth rate [1]. With the economic reform initiated in the early 1980s in China, the healthcare system had to adapt to a new economic approach, namely, shifting from a communal system to marketdriven competition.

Unfortunately, this disorientation caused several problems in Chinese society. The SARS outbreak in 2003 shocked the country's leaders, thereby exposing the inadequacies in the public health protection system and demonstrating government negligence that had left the healthcare system unprepared to deal with its core responsibilities [2, 3]. Thereafter, the government struggled to maintain a balance between meeting the people's immediate healthcare needs and developing the healthcare systems with a series of healthcare policies and reforms [4-6]. For example, after three years of planning, China unveiled its ambitious healthcare reform plan in April 2009 by committing an additional CN¥850 billion (approximately US\$125 billion) over a three-year period with the provisional goal of affordable and equitable basic healthcare for all by 2020 [3, 7]. Influenced by health policies and economic investments, healthcare science and services (HSS) research in China began to escalate and develop rapidly.

With the increase in HSS research in China, research collaboration also proliferated in this field. Scientists benefited from intellectual exchanges with foreign colleagues and reduced costs by sharing resources and technologies with other countries [8]. Apart from improving research capability, international collaboration may enhance productivity and visibility, although visibility improvement varies among countries and fields [9]. In recent decades, the robust relationship between collaboration and scientific research productivity and academic impact has been studied and documented by Lotka [10] and others. In general, collaboration exerts positive effects on teams' outputs and abilities, and cooperative scientific research results have relatively high academic impact, particularly those related to international collaboration. For example, the citations of a paper are partially related to the number of authors, institutions and countries participating in the paper. However, the effects depend on the collaboration type and the partners involved [11-13]. For example, Narin showed that multiple-institution papers are more highly cited than single-institution papers, and papers with a foreign collaborator are more highly cited than domestic papers $[11,14]$. Glänzel demonstrated that the influence of international collaboration on national citation performance also varies considerably between countries. In some cases, no quality advantage exists for one or both partners, such as in certain collaborations among developing or Eastern European countries [15]. Meanwhile, the collaboration patterns and influences on research productivity or academic impact also vary by discipline $[13,15]$. Therefore, understanding the collaboration characteristics of specific fields could inform the policies on partners' selection and research performance improvements, and could even contribute to economic development $[16,17]$.

This study was built on our previous work which analyzed the global progress and current research trends on health care sciences and services research [18]. Although the rapid growth and extensive collaboration in HSS research is observed in theory and practice in China, the publication trends, collaboration patterns and their effects on HSS research in this country remain unclear. Limited attention has also been focused on which groups of actors are at the center and at the periphery of the collaboration network. The previous study was a comprehensive scientomentric research from a global perspectives, while this study focuses on China's collaboration relationships in HSS research. Both collaboration relationship and publication patterns were studied on multiple levels and from several perspectives. With the availability of critical data, such as those from the Web of Science (WoS) of Thomson Reuters, scientometricians have attempted to explore the characteristics of international collaboration from various perspectives [9]. Given the importance of Chinese collaboration in the international context, the current study evaluated the publication trends, collaboration patterns and current research trends of Chinese HSS.

Thus, the objectives of this study are as follows: (1) to study the Chinese HSS publication trends from absolute and relative perspectives, (2) to explore the collaboration patterns and identify the core partners and institutions, and (3) to present the research foci of HSS in China. The results of this study could provide evidence on the current status and recent trends of publication and collaboration in China, as well as indications of this topic's popularity and citation performance.

\section{Methods}

\section{Data sources}

This study was based on the analysis of article-level data from the online version of the WoS database, which is owned by Thomson Reuters. WoS is a highly significant 
and frequently employed source database in reviewing scientific achievements and trends $[19,20]$. Therefore, HSS-related articles from WoS were suitable for the present study. Data in this study were acquired on February 2, 2015 using the following search strategy: $S U=$ Health Care Sciences \& Services AND CU = China $A N D$ PY $=2000-2014$. A total of 2416 related papers were extracted from the databases. Thereafter, the bibliographies were downloaded and imported into a bibliographic software program. The Health Care Sciences \& Services subject contains healthcare science, healthcare services and health policy-relevant research within the WoS database.

\section{Analysis Methods}

Scientometric methods have been extensively used recently to analyze scientific productions, collaborations and research topics [19, 21-29]. Scientometric and related indicators are also suitable for scientific literature analysis from both the macro- and micro-perspectives. In the present study, the performance of the publication and collaboration of HSS research in China is analyzed from both the quantity and academic impact perspectives. Quantity was determined by the number of publications and the growth trends were measured through two related parameters, namely, relative growth rate (RGR) and doubling time (Dt) [30]. The academic impact of the papers was measured using the total local citation score (TLCS), total global citation score (TGCS), and average global citation score (AGCS) [31]. Coauthorship and social network analysis were also used to study the collaboration at the country and institution levels [18]. Furthermore, co-words and cluster analysis were used in combination to identify the popular topics. Visualization technology, particularly knowledge mapping technology, was also used to show the results of the collaboration between countries or institutions and popular research topics. Thomson Data Analyzer (TDA) [32] and HistCite [33] were used as statistical analysis tools. The drawing tools used in this study include Ucinet [34] and VOSviewer [35].

\section{Growth speed indicators}

RGR is originally sourced from the study of financial investment and is effectively applied in botany to analyze the growth of individual plants [36]. In the current study, RGR was used to measure the growth rate of the number of articles with time. Meanwhile, Dt is directly related to RGR and is the time required for the number of articles to double [26, 29,37]. RGR and Dt are defined as follows:RGR $=(\operatorname{lnN} 2-\ln N 2) /(t 2-t 1)$ (Formula 1) $D t=(t 2-t 1) * \ln 2 /(\ln N 2-\ln N 1)$ (Formula 2), where $\mathrm{N} 2$ and $\mathrm{N} 1$ are the cumulative publications in two years, that is, $\mathrm{t} 2$ and $\mathrm{t} 1$, respectively. In the present analysis, $\mathrm{t} 2-\mathrm{t} 1$ is considered 1 year. Thereafter, RGR and Dt can be expressed as $R G R=\ln (N 2 / N 1)$ and $D t=\operatorname{In} 2 /$ $R G R$. A constant value for RGR in each subsequent year is an indication that the growth rate is exponential. Dt is a characteristic time for this exponential growth.

\section{Academic impact indicators}

The academic impact indicators used in this study include TLCS, TGCS and AGCS based on citation frequency. TLCS is the number of times that papers in a set included in a collection has been cited by other papers within the collection. TGCS is the number of times that papers in a set included in a collection has been cited in the WoS database. AGCS is the mean value of TGCS and indicates the average citation number of articles in the HSS areas. TLCS and TGCS have been the key indicators in evaluating the relevance of research papers [18].

\section{Collaboration performance indicators}

The term "co-authorship" is often used to denote multiple authors, institutions or countries appearing simultaneously in one paper; in this article, they are called co-authors, co-institutions and co-nations, respectively. Meanwhile, social network analysis (SNA) and the related centrality indicators were also used to analyze the collaboration performance of institutions and countries. As a "structural analysis" method, SNA has been successfully applied in various fields, such as sociology, information and library sciences, geography and other areas [38]. SNA has also been extensively used to investigate scientific collaboration networks and the relationship between individuals at the author, institution and country levels $[17,39,40]$. The current study analyzes trends in the extent of collaboration at all levels and the collaboration networks at the country and institution levels, because country and institution collaboration can reveal the collaboration at the macro- and meso-levels, respectively. The combination of the two levels can facilitate further understanding of trends, networks and core groups of international collaboration [41]. In the present study, network nodes represent institutions or countries, whereas ties represent the cooperation of institutions or countries. Degree centrality is defined as the number of ties of a node, representing the simplest notion of centrality because such a value simply refers to the number of neighbors of a node in the network. Degree centrality is a crucial indicator in analyzing the network, thereby reflecting the importance and influence of an institution or a country in the network [18].

\section{Results}

\section{Growth trends from multiple perspectives}

Table 1 shows the year-wise publications of the world and China in the HSS area, as well as those of China in 
Table 1 Chinese and worldwide publication trends in healthcare science and services, 2000-2014

\begin{tabular}{|c|c|c|c|c|c|c|c|c|c|c|c|c|}
\hline Year & $\begin{array}{l}\text { No. of } \\
\text { China }\end{array}$ & $\begin{array}{l}\text { Cumulative } \\
\text { China }\end{array}$ & $\begin{array}{l}\text { No. of } \\
\text { World }\end{array}$ & $\begin{array}{l}\text { Cumulative } \\
\text { World }\end{array}$ & $\begin{array}{l}\text { No. of } \\
\text { China all }\end{array}$ & $\begin{array}{l}\text { Cumulative } \\
\text { China all }\end{array}$ & $\begin{array}{l}\text { RGR } \\
\text { China }\end{array}$ & $\begin{array}{l}\text { RGR } \\
\text { World }\end{array}$ & $\begin{array}{l}\text { RGR } \\
\text { China all }\end{array}$ & $\begin{array}{l}\text { Dt } \\
\text { China }\end{array}$ & $\begin{array}{l}\text { Dt } \\
\text { World }\end{array}$ & $\begin{array}{l}\text { Dt } \\
\text { China all }\end{array}$ \\
\hline 2000 & 37 & 37 & 7730 & 7730 & 31953 & 31953 & - & - & - & - & - & - \\
\hline 2001 & 43 & 80 & 6814 & 14544 & 37407 & 69360 & 0.77 & 0.78 & 0.16 & 0.90 & 0.89 & 4.40 \\
\hline 2002 & 48 & 128 & 8235 & 22779 & 42316 & 111676 & 0.47 & 0.48 & 0.12 & 1.47 & 1.46 & 5.62 \\
\hline 2003 & 55 & 183 & 8903 & 31682 & 51843 & 163519 & 0.36 & 0.38 & 0.20 & 1.94 & 1.82 & 3.41 \\
\hline 2004 & 63 & 246 & 9162 & 40844 & 65036 & 228555 & 0.30 & 0.33 & 0.23 & 2.34 & 2.07 & 3.06 \\
\hline 2005 & 54 & 300 & 9949 & 50793 & 76268 & 304823 & 0.20 & 0.29 & 0.16 & 3.49 & 2.41 & 4.35 \\
\hline 2006 & 69 & 369 & 10920 & 61713 & 92630 & 397453 & 0.21 & 0.27 & 0.19 & 3.35 & 2.61 & 3.57 \\
\hline 2007 & 87 & 456 & 11570 & 73283 & 100981 & 498434 & 0.21 & 0.23 & 0.09 & 3.27 & 3.06 & 8.03 \\
\hline 2008 & 124 & 580 & 12775 & 86058 & 117710 & 616144 & 0.24 & 0.21 & 0.15 & 2.88 & 3.27 & 4.52 \\
\hline 2009 & 159 & 739 & 14272 & 100330 & 134307 & 750451 & 0.24 & 0.20 & 0.13 & 2.86 & 3.52 & 5.25 \\
\hline 2010 & 223 & 962 & 14618 & 114948 & 149457 & 899908 & 0.26 & 0.18 & 0.11 & 2.63 & 3.82 & 6.49 \\
\hline 2011 & 228 & 1190 & 15921 & 130869 & 173125 & 1073033 & 0.21 & 0.18 & 0.15 & 3.26 & 3.94 & 4.72 \\
\hline 2012 & 351 & 1541 & 18337 & 149206 & 199132 & 1272165 & 0.26 & 0.17 & 0.14 & 2.68 & 4.07 & 4.95 \\
\hline 2013 & 348 & 1889 & 19317 & 168523 & 236653 & 1508818 & 0.20 & 0.17 & 0.17 & 3.40 & 4.06 & 4.02 \\
\hline 2014 & 527 & 2416 & 19307 & 187830 & 264943 & 1773761 & 0.25 & 0.16 & 0.11 & 2.82 & 4.28 & 6.14 \\
\hline
\end{tabular}

No. of China: number of articles published by China on HSS; No. of World: number of articles published by the world on HSS; No. of China all: number of articles published by China on all fields

all fields, including the year number, cumulative number, RGR and Dt from 2000 to 2014.

\section{Absolute perspective}

Table 1 presents the number of papers on HSS in China and in the world from 2000 to 2014. During the past two decades, the number of published papers related to HSS increased from 37 in 2000 to above 500 in 2014. Table 1 also shows that only a few papers were produced before 2005, which was the formative stage of the Chinese HSS research. From 2005 to 2010, which was the development stage of Chinese HSS research, the annual output of papers did not exceed 200. Thereafter, the number of papers increased rapidly (i.e., after 2010), when the Chinese HSS research entered the rapid development stage. Nevertheless, the inflection point of maturity, where growth begins to taper off, has not yet been reached.

\section{Relative perspective}

Figures 1 and 2 show the Chinese HSS papers as a percentage of Chinese papers in all fields and the world HSS papers. The percentage of Chinese HSS papers reveals the publication trends from a relative perspective, which can precisely and relatively reflect the development trends of Chinese HSS research. The percentage of Chinese HSS papers exhibited up and down trends, thereby implying a decrease and a rapid increase, respectively, before and after 2005. The increasing stage could be divided into two stages, namely, constant growth (2005-2010) and fluctuant growth (2010-2014) stages. These results are considered based on the publication trends, thereby suggesting that Chinese researchers focused considerable attention and effort to HSS studies compared to other fields in China and to HSS research in the world.

\section{Dynamic perspective}

The growth perspective indicates that the average values of worldwide RGR and Dt were 0.29 and 2.95, respectively. The average values of RGR and Dt for the Chinese HSS research were 0.30 and 2.66 , respectively (Table 1 ). Meanwhile, the average values of RGR and Dt for all fields in China were 0.15 and 4.89. In the HSS field, the global growth rate showed a significant decrease during the last 15 years. Meanwhile, China revealed up and

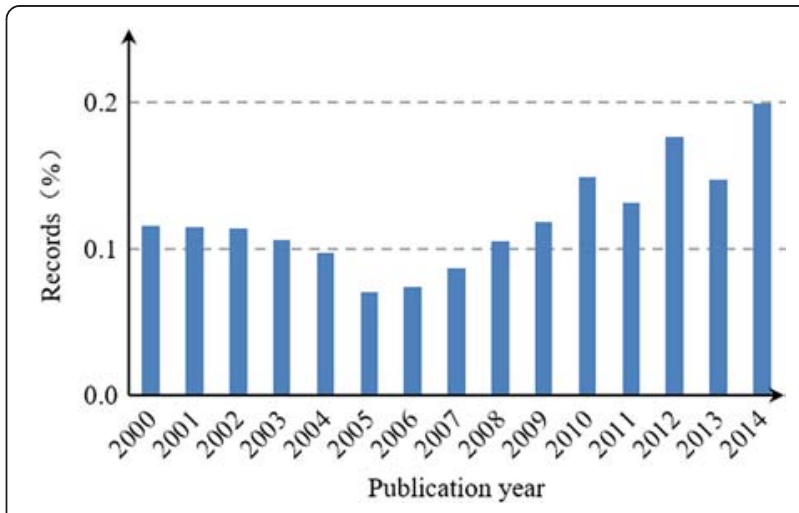

Fig. 1 Chinese HSS papers as a percentage of Chinese papers in all fields 


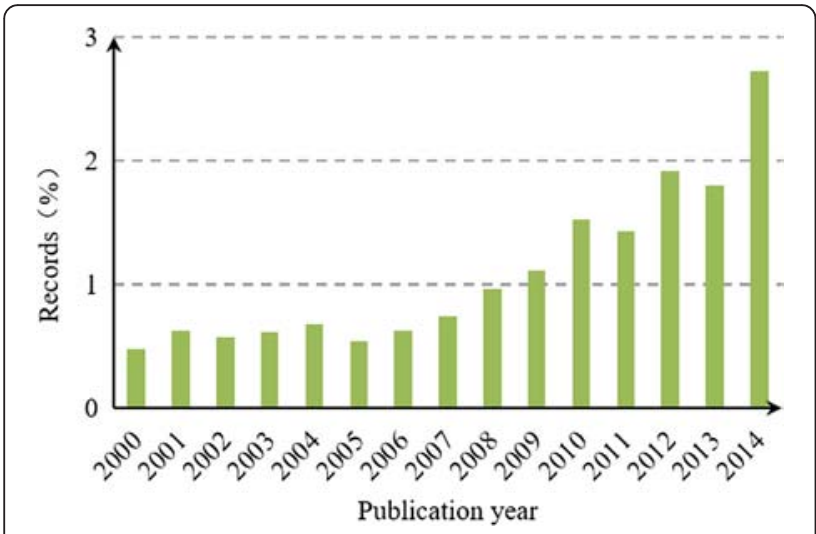

Fig. 2 Chinese HSS papers as a percentage of the world HSS papers

down trends that indicate a decrease during the first 5 years (from 2001 to 2005), which was a constant trend after 2005 and a trend exceeding that of the world in 2008. The growth rates of HSS research in both China and the world were higher than those of all fields in China. In addition, the growth rate of HSS research in China showed an impressive increase of $21 \%$ during the last 15 years. This figure was significantly higher than that of HSS research in the world $(7 \%)$ and of all fields in China (16\%).

\section{Collaboration and performance Collaboration trends}

Chinese collaboration with other countries in HSS research exhibits up and down trends; however, the general tendency of the trends is to increase, particularly after 2003. Figure 3 shows the percentage of collaborative papers, including those involving co-authors, co-institutions or co-countries. The percentage of co-authored papers increased from $68 \%$ in 2000 to $95 \%$ in 2014. The percentages of co-institutional papers and co-national papers showed increasing trends from 41 to $67 \%$ and from 27 to $43 \%$, respectively. These results suggest that the collaboration between institutions and countries has increased significantly since 2003.

Figure 4 shows the trends of the average number of authors, institutions or countries per paper. The average number of authors per paper increased from 2.73 in 2000 to 5.16 in 2014, whereas the average number of countries per paper only increased from 1.46 in 2000 to 1.64 in 2014. More than half of the papers are the result of the cooperation within China; hence, these papers have an average of approximately two institutions and four to five authors.

\section{Partner Countries}

In terms of quantity, China collaborated with 84 countries in HSS research over the last 15 years. Among China's partners, the US played a major role, accounting for approximately one-fourth of the Chinese joint publications in HSS. The UK, the second largest partner of China, was left significantly behind. Australia and Canada were also important partners of China. Overall, China's top 10 partners contributed to more than half of the joint publications. In terms of academic impact, collaborations with the US has the highest TGCS because of the numerous papers published, followed by collaborations with the UK, Australia and Canada. The AGCS of countries are listed in descending order and includes those of the Netherlands, Switzerland, the UK and Japan, among others. Papers from China which were written in collaboration with these countries often have considerably high academic impact and influence (Table 2).

The collaboration relationships among a core group of countries (top 30) were visualized using Ucinet, which allowed for a number of analytical procedures to be undertaken to determine the types of shared relationships among the countries or regions [42]. Fig. 5 presents the national or regional cooperative relationship with China in HSS research. In this figure, the size of the nodes stands for the centrality degree of a specific

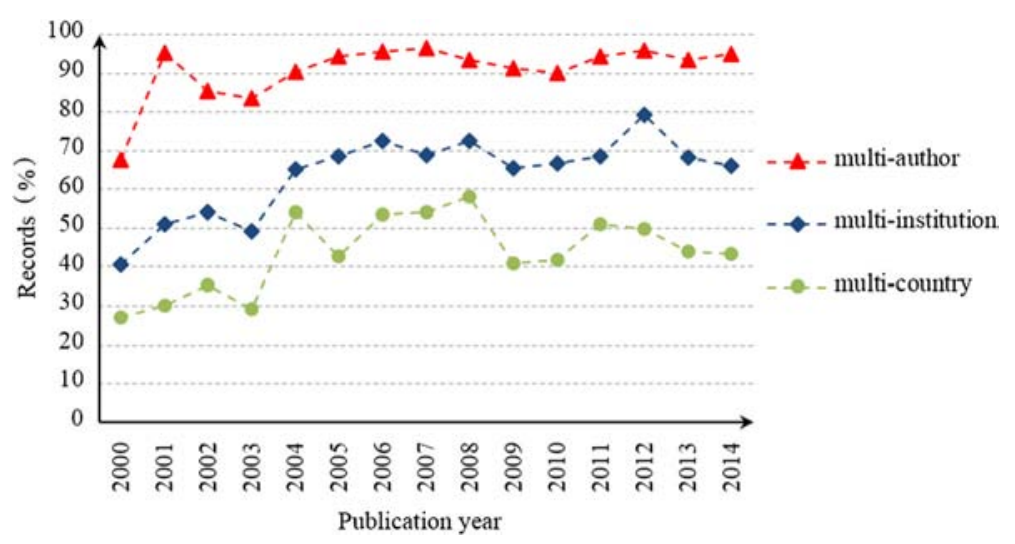

Fig. 3 Percentage of multi-entity in Chinese HSS papers from 2000 to 2014 


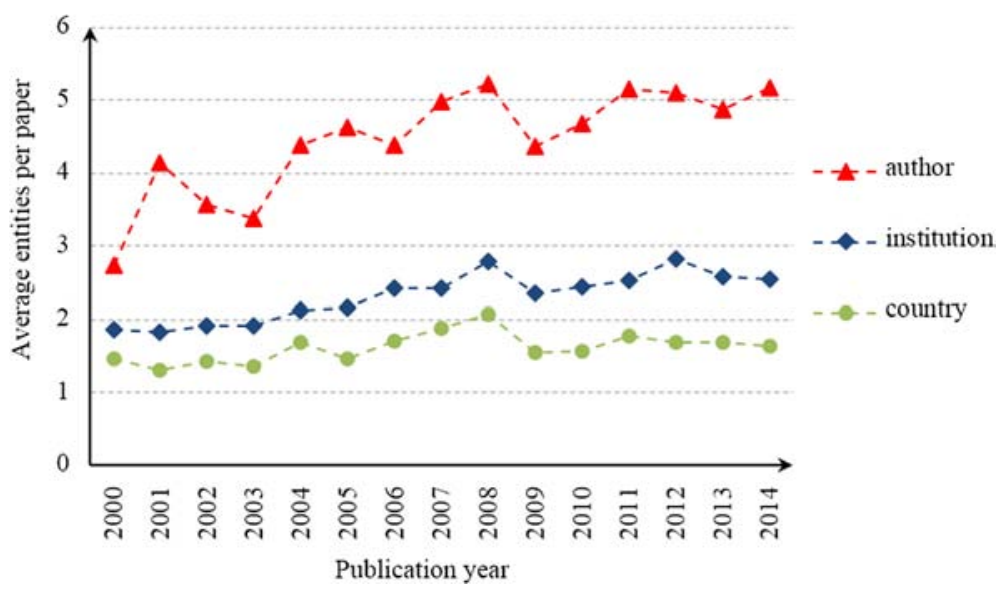

Fig. 4 Average number of different entities per paper in Chinese HSS papers from 2000 to 2014

country (i.e. the extent to which it is involved in HSS publications related to China), whereas the thickness of the links stands for the collaboration strength between countries. China is located at the core position in the network and cooperates frequently with the US, the UK, Australia, Canada, Germany, Netherlands, Switzerland and Japan, among others. Meanwhile, Taiwan, Singapore and other countries are located at the periphery. This situation means that China's cooperation with this second group of countries in studying HSS research is not as frequent as that with the first group. Other countries or regions located in the outermost loci of the cooperation network cooperate less with China in this area.

\section{Prominent institutions}

One thousand seven hundred eighty-nine institutions contributed to the set of publications considered in this study. Table 3 shows the top 20 institutions, each of which has published over 30 papers, and which together account for over two-thirds of all publications. The Chinese University of Hong Kong (CUHK) performed extremely well and significantly exceeded other institutions with a total of 333 papers published. This finding suggests that CUHK is the most prominent institution in terms of HSS research among Chinese institutions. CUHK is followed by the University of Hong Kong, Peking University, Fudan University and other universities. Among non-academic institutions, China's Ministry of Health had the highest citations per paper and substantially exceeded other institutions. This ministry is followed by Harvard University, Wayne State University and Shandong University. Meanwhile, CUHK, University of Hong Kong, Chinese Centre for Disease Control and Prevention (CDC), and Prince Wales Hospital also had relatively high AGCSs. The AGCSs of articles published solely by researchers from Mainland China's institutions were relatively low, thereby indicating that the articles produced in cooperation with foreign

Table 2 Top 10 productive partners of China in healthcare science and services, 2000-2014

\begin{tabular}{|c|c|c|c|c|c|c|c|c|}
\hline Rank & Partner & Joint Publications & Percent & Recs 1st & Percent 1st & TLCS & TGCS & AGCS \\
\hline 1 & US & 566 & 23.43 & 265 & 46.82 & 316 & 3477 & 6.14 \\
\hline 2 & UK & 172 & 7.12 & 58 & 33.72 & 124 & 1523 & 8.85 \\
\hline 3 & Australia & 149 & 6.17 & 51 & 34.23 & 63 & 898 & 6.03 \\
\hline 4 & Canada & 84 & 3.48 & 31 & 36.90 & 40 & 653 & 7.77 \\
\hline 5 & Singapore & 53 & 2.19 & 21 & 39.62 & 9 & 163 & 3.08 \\
\hline 6 & Taiwan & 46 & 1.90 & 23 & 50.00 & 2 & 143 & 3.11 \\
\hline 7 & Japan & 45 & 1.86 & 15 & 33.33 & 20 & 378 & 8.40 \\
\hline 8 & Switzerland & 45 & 1.86 & 12 & 26.67 & 34 & 459 & 10.20 \\
\hline 9 & The Netherlands & 38 & 1.57 & 10 & 26.32 & 5 & 418 & 11.00 \\
\hline 10 & Germany & 35 & 1.45 & 10 & 28.57 & 3 & 159 & 4.54 \\
\hline
\end{tabular}

Joint Publications: number of articles collaborated with China; Percent: percentage of articles; Recs 1st: number of articles collaborated with China as first country; Percent 1st: percentage of articles collaborated with China as first country; TLCS: Total Local Citation Score, which is the number of times cited by other papers in the local collection; TGCS: Total Global Citation Score, which is the citation frequency based on the full WoS count at the time the data were downloaded; AGCS is the average citation frequency of an article 


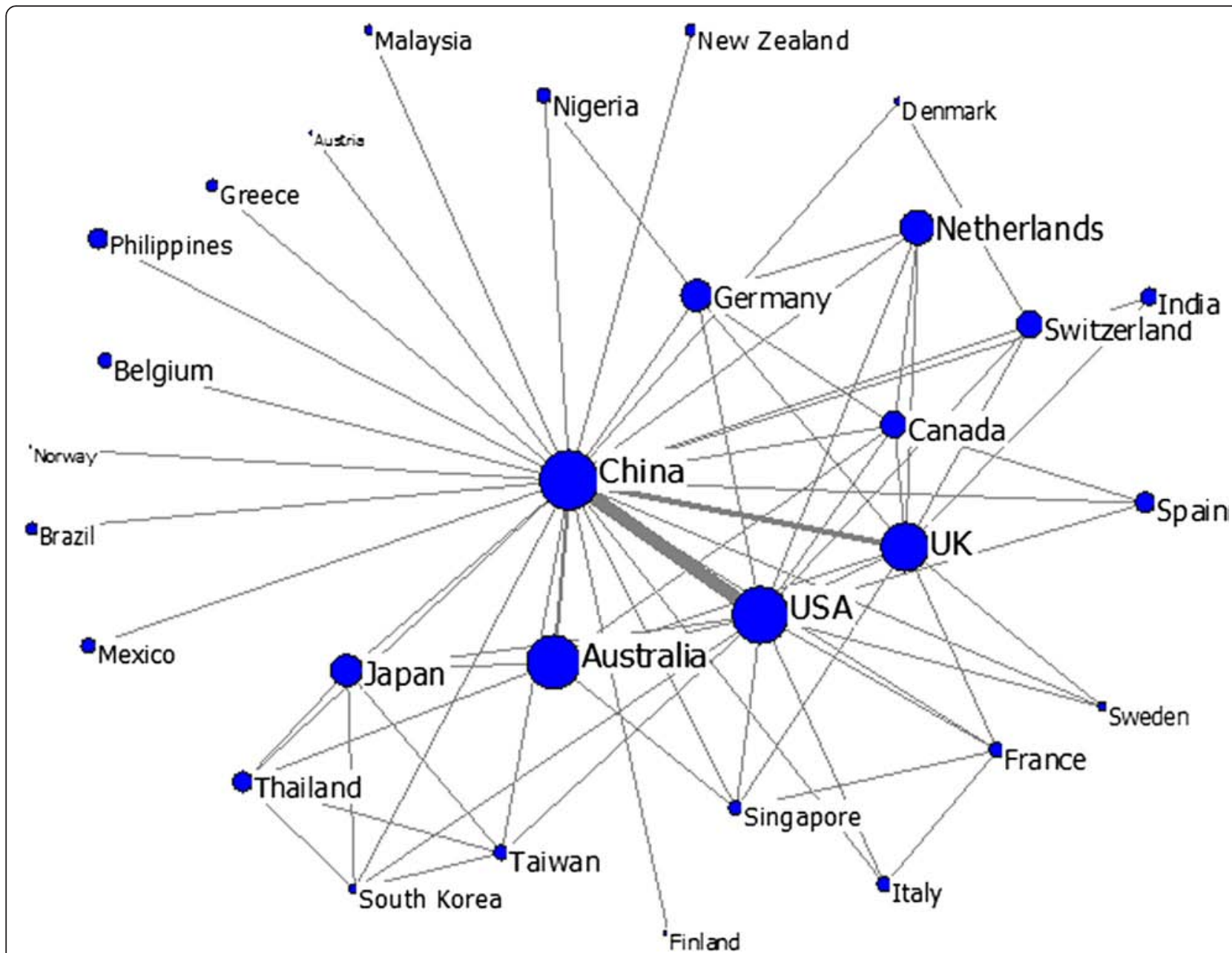

Fig. 5 National collaboration map of China in HSS research (The size of the nodes represents the degree centrality of the countries, and the thickness of the lines represents the co-occurrence frequency between countries)

institutions, particularly the prominent ones, have relatively high academic impact.

Figure 6 represents the mapping of the top 30 institutions involved in the cooperation of the network in HSS research with China. Chinese Peking University, Fudan University and University of Hong Kong are evidently in the core of the network, thereby indicating that these institutions cooperate with considerable frequency with other academic institutions. This finding also means that these institutions play a significant role in the process of HSS knowledge transfer on a global scale. Meanwhile, the entire network can be divided into two institutional groups of cooperation. One group mainly comprises institutions in Mainland China, such as Peking University, Fudan University, Huazhong University of Science and Technology, Shandong University, Sun Yat Sen University and the Chinese CDC, among others. The other group primarily comprises various Hong Kong institutions, such as CUHK, University of Hong Kong, Hong Kong Polytechnic University, Hong Kong Baptist
University, City University of Hong Kong, Hong Kong Institute of Education; and a few foreign institutions, such as Harvard University and National University of Singapore.

\section{Research topics}

The authors' keywords could offer information on how the authors conceptualize their own research, and such keywords have been proven vital in monitoring the development of science [43-45]. Therefore, the papers' topics can be observed from the authors' keywords through cluster analysis. The 55 authors' keywords are divided into four groups that represent popular research topics on HSS research in China (Fig. 7).

Group 1 (red) - Chinese health topics, including healthcare reform-related topics (e.g., health insurance, primary care, rural health, hospital problems), priority diseases or public health problems, health systems performance and Chinese cultural questions for health, are included in this group. In the past decades, healthcare reforms were the 
Table 3 Top 20 productive institutions with China in healthcare science and services, 2000-2014

\begin{tabular}{|c|c|c|c|c|c|c|c|c|}
\hline No. & Institution & Recs & Percent & Recs 1st & Percent 1st & TLCS & TGCS & AGCS \\
\hline 1 & Chinese Univ Hong Kong & 333 & 13.78 & 260 & 78.08 & 144 & 2537 & 7.62 \\
\hline 2 & Univ Hong Kong & 255 & 10.55 & 195 & 76.47 & 154 & 1938 & 7.60 \\
\hline 3 & Peking Univ & 222 & 9.19 & 119 & 53.60 & 91 & 1005 & 4.53 \\
\hline 4 & Fudan Univ & 156 & 6.46 & 103 & 66.03 & 63 & 731 & 4.69 \\
\hline 5 & Sichuan Univ & 81 & 3.35 & 54 & 66.67 & 14 & 235 & 2.90 \\
\hline 6 & Hong Kong Polytech Univ & 79 & 3.27 & 55 & 69.62 & 24 & 392 & 4.96 \\
\hline 7 & Zhejiang Univ & 78 & 3.23 & 57 & 73.08 & 16 & 139 & 1.78 \\
\hline 8 & Huazhong Univ Sci \& Technol & 57 & 2.36 & 43 & 75.44 & 30 & 200 & 3.50 \\
\hline 9 & Sun Yat Sen Univ & 56 & 2.32 & 28 & 50.00 & 23 & 247 & 4 \\
\hline 10 & Shandong Univ & 47 & 1.95 & 26 & 55.32 & 78 & 385 & 8.19 \\
\hline 11 & Chinese Ctr Dis Control \& Prevent & 45 & 1.86 & 29 & 64.44 & 21 & 334 & 7.42 \\
\hline 12 & Shanghai Jiao Tong Univ & 44 & 1.82 & 26 & 59.09 & 23 & 203 & 4.61 \\
\hline 13 & Wayne State Univ & 39 & 1.61 & 15 & 38.46 & 48 & 345 & 8.85 \\
\hline 14 & Minist HIth & 38 & 1.57 & 8 & 21.05 & 90 & 569 & 14.97 \\
\hline 15 & Prince Wales Hosp & 37 & 1.53 & 9 & 24.32 & 23 & 259 & 7.00 \\
\hline 16 & Xi An Jiao Tong Univ & 36 & 1.49 & 23 & 63.89 & 7 & 76 & 2.11 \\
\hline 17 & Second Mil Med Univ & 35 & 1.45 & 29 & 82.86 & 11 & 134 & 3.83 \\
\hline 18 & Harvard Univ & 34 & 1.41 & 7 & 20.59 & 54 & 339 & 9.97 \\
\hline 19 & Nanjing Med Univ & 34 & 1.41 & 18 & 52.94 & 9 & 134 & 3.94 \\
\hline 20 & Natl Univ Singapore & 34 & 1.41 & 14 & 41.18 & 9 & 109 & 3.21 \\
\hline
\end{tabular}

Recs: number of articles; Percent: percentage of articles; Recs 1st: number of articles as first institution; Percent 1st: percentage of articles as first institution; TLCS: Total Local Citation Score, which is the number of times cited by other papers in the local collection; TGCS: Total Global Citation Score, which is the citation frequency based on the full WoS count at the time the data were downloaded; AGCS is the average citation frequency of an article

major issues in China. Various policies adopted by health policymakers indicate that China's healthcare system reform passed through three periods [46] and numerous milestone events also happened during these periods [3-5, 7] (For details, see Appendix 1). Meanwhile, setting the priority areas and evaluating the effects of health reform are two vital topics in the health reform process. Accordingly, it is not surprising that articles on topics related to the Chinese health care reform figure prominently among Chinese HSS publications.

The analysis also indicates that Chinese HSS publications also focus on specific diseases and health issues, such as breast cancer, mental health, HIV/AIDS, tuberculosis, schistosomiasis and condom use, among others. Furthermore, healthcare system performance assessment is an important tool used to evaluate the effects and performance of healthcare reforms. To monitor and evaluate the reforms effects or health system status, the Chinese government and its universities have done a lot of research on health systems performance assessments. As showing in Fig. 7, Chinese healthcare systems may be evaluated from the aspects of health equity, health access, health cost effectiveness, patient satisfaction and other aspects.
Group 2 (green) - Quality of life (QOL)-related topics, such as the measurement of QOL or health-related quality of life, QOL measurement tools and reliability and validity of the QOL measurement tools, are included in this group. The QOL outcomes are significant topics in HSS research. The World Health Organization (WHO) defines QOL as an "individual's perception of their position in life in the context of the culture and value systems in which they live and in relation to their goals, expectations, standards and concerns" [47]. Economic development has led the Chinese to focus considerable attention on QOL. Therefore, QOL is a crucial research topic in China, particularly in recent years. Chinese researchers mainly focus on developing or improving the measurement tools based on the world's popular tools and Chinese situations, such as SF-36, SF-12, SF-6D, WHOQOL and EQ-5D [48]. Researchers often use reliability and validity indicators to evaluate the effects of the developed or modified tools. Thereafter, they can measure and understand the Chinese's QOL and even compare it with that of people from other countries. QOL research mainly focuses on children and the aging population $[49,50]$. Significant attention has also been focused on QOL of patients with cancer, schizophrenia and depression $[51,52]$. 


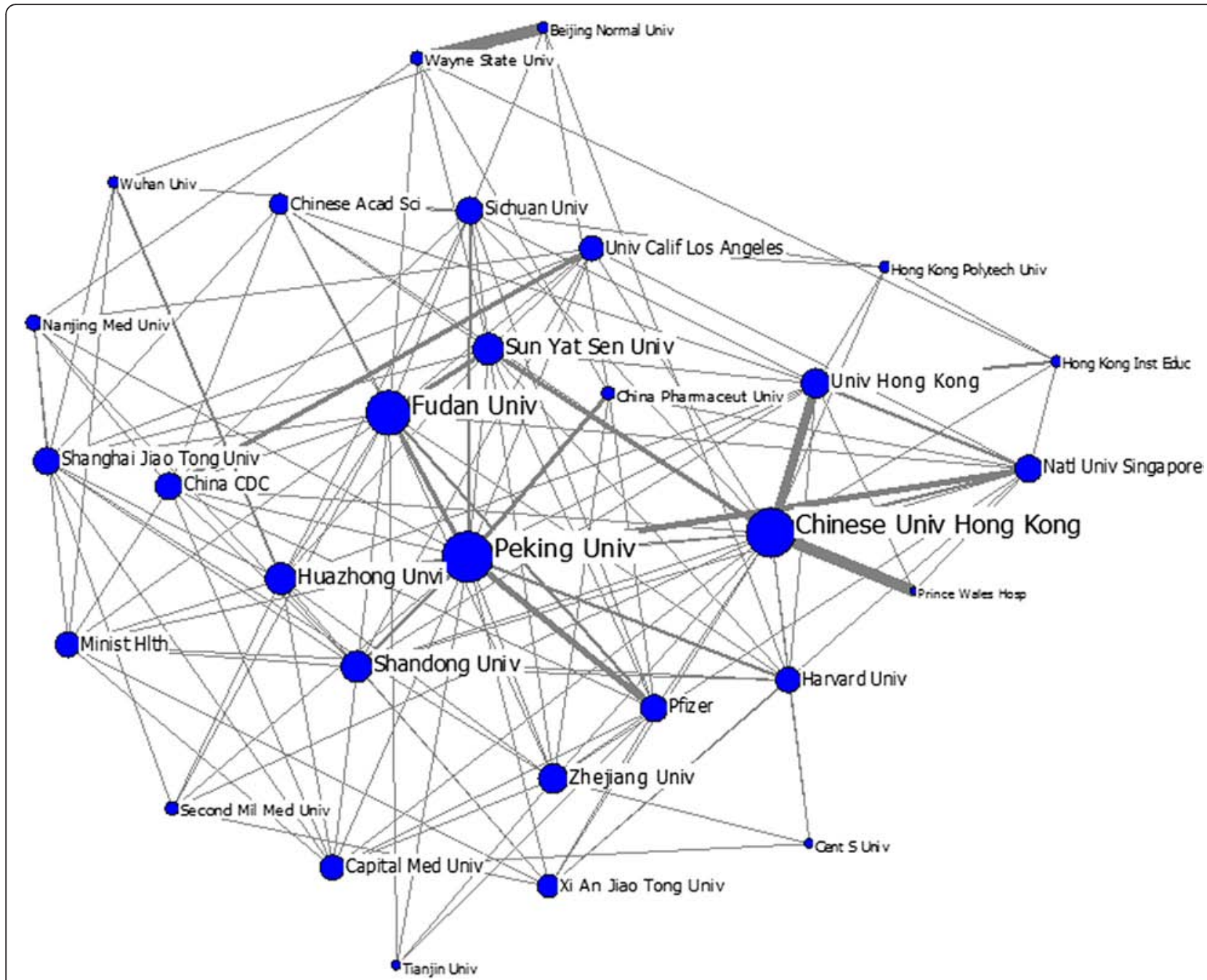

Fig. 6 Institutional collaboration map of China in HSS research (The size of the nodes represents the degree centrality of the institutions, and the thickness of the lines represents the co-occurrence frequency between institutions)

Group 3 (blue) - Topics related to the elderly, including palliative or end-of-life care and medical education and methods, are included in this group. Hong Kong researchers devote significant attention to the problems of old people, such as old people's QOL, disability trends [53], lifestyle risk factors [54], willingness to pay for specific primary care and preventive services [55], and others. Mainland China and Hong Kong closely cooperate in the area of palliative or end-of-life care. Palliative care provides relief from pain and distressing symptoms, as well as offers psychological and spiritual support to enhance patients' QOL. Meanwhile, the needs, current knowledge and attitudes of old people who come from staffed homes in Hong Kong are marked differently [56]. Studies in Hong Kong determined that cancer patients have a relatively high level of palliative care, which has played a role in improving end-of-life cancer care in this city [57, 58]. Developing palliative care for end-stage diseases has also attracted the attention of Hong Kong researchers [59]. Both Mainland China and Hong Kong attach importance to medical education, as observed in the new medical curriculum evaluation [60], evidence-based medicine practice, barriers identification and teaching/learning assessment [61, 62].

Group 4 (yellow) - Research methods, including systematic review, meta-analysis and randomized controlled trial, are included in this group. Systematic review and meta-analysis have been extensively used by Chinese researchers in HSS. Moreover, an increasing number of Chinese researchers tend to use these methods to write articles because of their advantage in publishing science citation index/social sciences citation index (SCI/SSCI) articles. Several researchers also devote attention to the bias in meta-analysis and attempt to test and modify this method [63, 64]. 


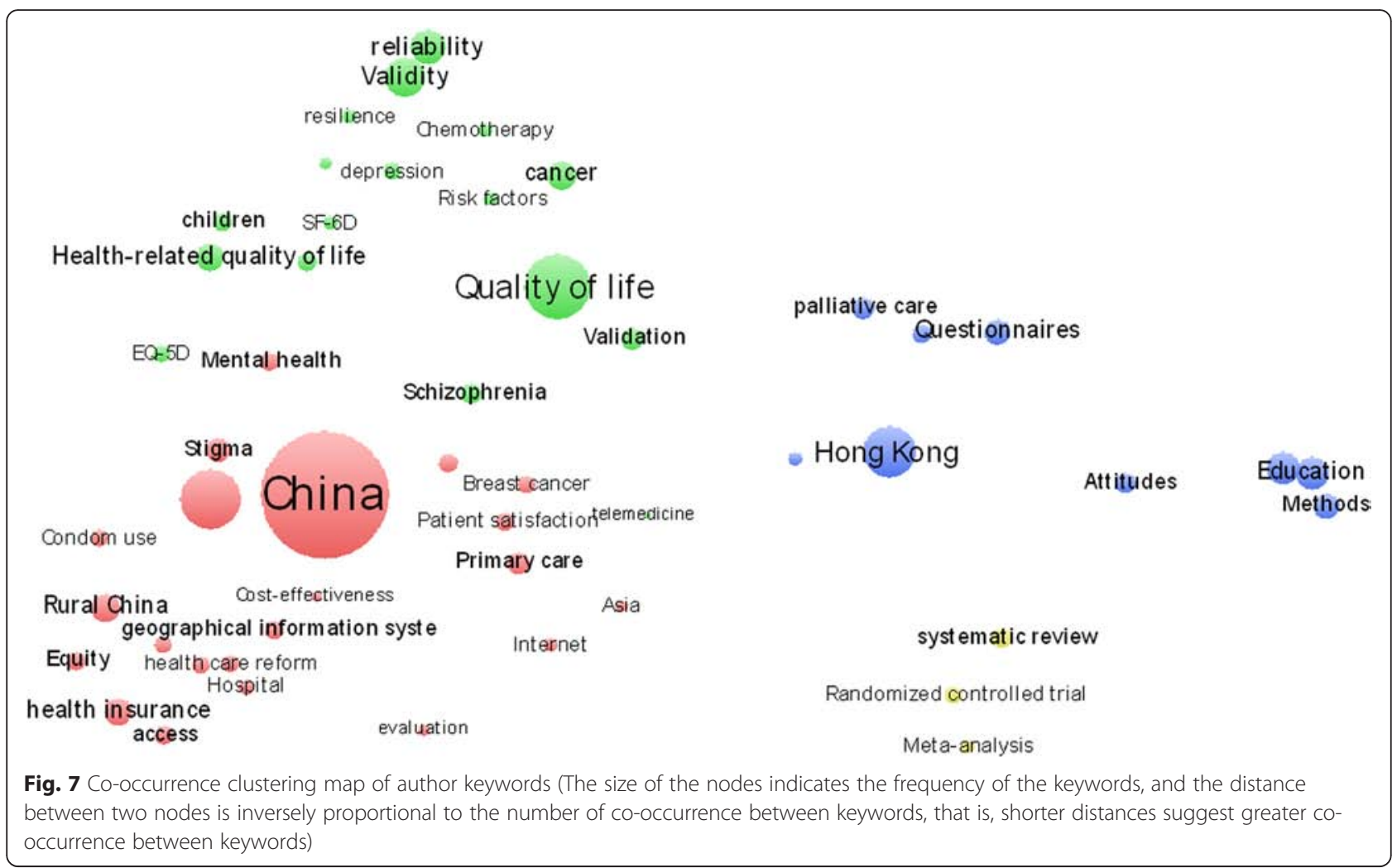

\section{Discussion}

\section{Good performance and bright future from multiple growth perspectives}

China has performed well in the HSS field, thereby indicating a continuously rising trend that has increased exponentially in the last 15 years. The growth rate of HSS research in China is significantly faster than that of HSS research in the world and of other fields in China. Recent trends in Chinese HSS research generally suggest a bright future in terms of quantity compared to the HSS research in the world and with other fields in China.

Many factors may have contributed to the rapid growth of international Chinese publications in the HSS fields, such as health policies and reforms, health projects and funds, international collaboration, research evaluation policies or mechanisms, graduate student enrolment expansion and other factors. First, the Chinese healthcare reforms in the HSS field commenced in the 1980s and China has undergone three reform periods [46]. Meanwhile, numerous milestone events occurred during these periods. In 2006, health officials and decision-makers realized that the previous reforms were unsuccessful; thus, a new round of reforms began [4,5]. In April 2009, after three years of planning, China unveiled its ambitious healthcare reform plan by committing to invest an additional CN $¥ 850$ billion (approximately US $\$ 125$ billion) over a three-year period with the provisional goal of providing affordable and equitable basic health care for all by 2020 [3, 7]. Therefore, these remarkable events have been highly considered by scholars and healthcare institutions, as well as contributed to the growth of Chinese HSS research.

Second, the consistent increase in investments in various healthcare fields enabled China to launch additional health projects and provide funds to support Chinese researchers in conducting high academic impact research. For example, the National Natural Science Fund and the Ministry of Health of China established health management and policy category funds to support HSS research; the financing amount for this program increases annually.

Third, the collaboration between China and other countries or international institutions has become increasingly frequent. The WHO, World Bank (WB) and China Medical Board (CMB) provide training and funds to Chinese researchers. For example, the WB/DFID China Rural Health Project (2008 to 2013) is a typical (and very large) program, which is funded by the Chinese government, a WB loan and a grant from the UK Department of International Development (DFID) [65]. This project aims to provide experience and a model for promoting rural health reform in areas in China with different development levels. During this process, WB and the UK government supplied financial and technical/academic support for China. CMB also supported Chinese researchers in universities to study 
health policy and system science-related fields [66]. These international activities and collaborations may assist Chinese researchers to enhance their research skills and publish additional international papers.

Chinese research evaluation policies also encourage students to publish international papers. This case is evident in the increasing number of universities requiring additional staff members and doctoral and master's students to publish SCI/SSCI papers as one of their requirements for graduation [67]. Therefore, the number of international papers increased with the expansion of graduate studies enrolment.

\section{Collaboration between Chinese and foreign researchers is becoming increasingly frequent}

The collaboration trends between countries, institutions and authors develop along with the publication growth trends. Moreover, the cooperation of authors is evidently higher than that of institutions and countries. Therefore, Chinese research capacity and international influence in HSS research may continue to strengthen. However, the collaboration of authors is mostly conducted within institutions or countries. The collaboration of China with over two countries in one paper is still infrequent. Given that productivity and are positively related to extent and patterns of collaboration s, Chinese researchers should improve the extent of collaboration with foreign countries and institutions, particularly with developed countries and well-known institutions.

\section{Collaboration and performance with core partners and institutions}

China's leading partners in HSS research are developed countries, with the quantity of papers resulting from cooperation with the US and the UK leading the way. The academic impact of papers is also generally high for European countries, such as Switzerland, the Netherlands and others. Therefore, international collaboration with these partners could improve the academic impact of Chinese HSS research output. Hence, international collaboration is still necessary for China to enhance its HSS research capacity. Meanwhile, the quantity of papers resulting in cooperation with Asian countries is relatively low, and the academic impact of these papers also needs improvement. The aforementioned situation can also be observed in the analysis of collaboration networks; hence, developed countries have conducted considerable research in this field with China.

This finding is consistent with parallel findings regarding regular scientific research, which is positively correlated with the level of economic development [68]. As a developing country with a rapidly expanding economy in the last 15 years, China's strategy to solve its domestic health problems involves utilizing its high output in the health reform domain and cooperating with several developed countries for its health reform needs. Therefore, China could strengthen its collaboration relationship with the aforementioned countries to improve the academic impact of research. In this process, Chinese researchers could also learn advanced methods and valuable experience.

The concentration of HSS research in China is primarily based in universities. Among the top 20 institutions in this field, 17 are universities and the remaining 3 are R\&D organizations. A few elite Chinese institutions, including CUHK, University of Hong Kong, Peking University and Fudan University, contributed approximately half of the Chinese studies and have collaborated with many international institutions. Additionally, the collaboration between the institutions of Mainland China and Hong Kong was frequent and close; however, the international collaboration of the former's institutions was weaker than that of latter's. Moreover, the papers published by China's Ministry of Health have a relatively high academic impact because it is a trusted source of information, and most of the ministry's papers were developed in collaboration with the US and the UK. However, papers from Mainland China are considered low academic impact papers. Mainland China merely has seven institutions, whereas numerous Hong Kong institutions play an important role in Chinese HSS research. Therefore, Mainland China's institutions should consider strengthening their collaborations with renowned institutions in the HSS field.

\section{Popular research topics are associated with China's healthcare reforms}

The analysis of keywords shows that popular Chinese health reform-centered topics were studied during the last decades. In spite of its extensive range, HSS research in China relatively focuses on healthcare reform, priority diseases (e.g., breast cancer, HIV/AIDS, tuberculosis, schistosomiasis, etc.), health systems performance, QOL and measurement tools, palliative or end-of-life care, old people problems, research methods and other related topics, particularly those associated to China. These topics drew significant attention from researchers and policymakers.

Healthcare system reform in China has been the most important topic during the last 30 years, particularly after the latest reform in 2009. China's healthcare system reform has achieved major milestones, particularly in health insurance, under the government's leadership. However, further analysis of the popular topics of the related articles highlighted gaps and challenges that need to be addressed to achieve China's stated reform goals. First, despite the extensive achievement in the coverage of health insurance in China, particularly the 
New Cooperative and Medical Scheme (NCMS) and Urban Resident Basic Medical Insurance (URBMI), the effects of health insurance on the reduction of financial risks is still unclear [69-72]. Second, although the objective of the pharmaceutical sector to control drugs is correct, the methods and the effectiveness of such methods are unclear [73, 74] and relatively little has been published in this area. Third, human resources shortage exists in China; hence, this problem is a major obstacle in strengthening the public health and primary health care of the country [75]. In addition, retaining qualified health professionals in the rural areas, particularly in the poor and underdeveloped regions, has been difficult because of socioeconomic reasons and the lack of a proper healthcare infrastructure [3]. Even with the availability of staff members, the lack of incentives (e.g., higher wages, work benefits, paid vacations, etc.) for primary healthcare workers to deliver public health services may be the main hindrance in retaining healthcare human resources in the rural areas. Fourth, reforming public hospitals is one of the key issues in controlling the increase in healthcare expenditures, improvement in the academic impact of care, and reduction of waste and inefficient work performance [3]. The reform of public hospitals, particularly county and city government hospitals, needs significant attention and considerable effort to improve the academic impact of service delivery. Finally, health services systems (including provision and utilization) in China are disorganized, and the referral systems and the function orientation of different types of hospitals are still unclear. Relatively little has been published on these important topics to date, so these fields may be important frontiers for future Chinese HSS research.

\section{Conclusions}

This study shows the publication trends, collaboration patterns and research foci of HSS research in China form multiple perspectives and levels. These results could assist both Chinese and foreign researchers, decision-makers and students understand the collaboration networks, select research themes and determine their partners in HSS research. Therefore, policymakers and researchers could foster a promising type of international collaboration network and improve the research performance for HSS research related to China.

\section{Appendix 1}

\section{The history and milestone of Chinese healthcare reforms} from 1980 to 2015

In the past decades, healthcare reforms were the major issues in China. Various policies adopted by health policymakers indicate that China's healthcare system reform passed through three periods [46] classified as follows: (1) 1980s to 1993: market participation; (2) 1994-2005: market orientation (profound marketization); and (3) 2006 to present: government-driven market involvement. Numerous milestone events also happened during these periods. For example, China's healthcare system reform began from the early 1980 s to 1985 . This period was regarded as the first stage of the reforms because the government officially approved the implementation of the healthcare sector reform. Healthcare financing was transferred from the central government to the local governments. In 1990, many discussions were conducted focusing on the dominant actor that should supervise the implementation of the healthcare system reform. This implementation was determined by the central government that set the main principles for "market participation" in 1992. In 1994, China began to reduce expenditures in the healthcare system. In 1997, the Chinese government encouraged the healthcare market to become market-oriented. In 2000, the privatization of several hospitals was allowed, thereby resulting in the emergence of many private hospitals since then. In 2006, health officials and decision-makers realized that the previous reform was unsuccessful; thus, they implemented a new round of reforms [4, 5]. In April 2009, China unveiled its new healthcare reform plan with the provisional goal of providing affordable and equitable basic health care for all by 2020 [3, 7]. This reform was anchored on five interdependent aspects: expanding healthcare coverage to over $90 \%$ of the population, establishing a national essential medicine system to meet all the citizens' primary needs for medicine, improving primary care delivery system to provide basic health care and to manage referrals to hospitals' specialists, making public health services available and equitable to all, and steering public hospitals reforms [7, 76, 77]. Before announcing the new healthcare system reform, the Chinese government was faced with widespread public discontent that stemmed from the following factors: unaffordable access to health care, major financial risks associated with out-of-pocket health expenditures, and growing inequalities in accessing healthcare and health services across populations with different socioeconomic status, as well as between urban and rural areas [78-83]. Meanwhile, a few of the previously eradicated infectious diseases had re-emerged, whereas non-communicable diseases (NCDs) increased unabatedly [84-86]. In 2003, the SARS outbreak shocked China's leaders, thereby exposing the inadequacies in the public health protection system and demonstrating government negligence that had left the health system unprepared to deal with its core responsibilities [2, 3]. Hence, examining the reform priorities against the problems and their causes in the pre-reform system led health authorities 
to determine that the current reforms are considerably headed in the right direction. The next phase of reforms, which was announced in detail in 2012 and 2013, intended to further improve the 2009 reforms [87, 88]. The 2015 health reform focuses on promoting government hospital reform (including county and city hospitals), thereby improving the universal health insurance system, strengthening the essential medications system, improving the pharmaceutical supply system, promoting an equitable primary public health services, establishing hierarchical medical systems and referral mechanisms, establishing proper health worker training and wage payment systems, promoting the development of the health services industry, and accelerating the development of population health information systems [89].

\section{Competing interests}

The authors declare that they have no competing interests.

\section{Authors' contributions}

LY and QY initiated and designed this study. QY participated in the study design, collected the data, conducted the data analysis and wrote the manuscript. KC, QY, JS, ZFH and ZYL contributed to the data analysis and the revision of the manuscript. All authors were involved in data interpretation and have read and given their final approval of this paper.

\section{Authors' information}

Kai Chen (KC) M.P.H, Ph.D., is a candidate in School of Medicine and Health Management, Tongji Medical College, Huazhong University of Science and Technology, and deputy director of Division of Rural Health, Department of Primary Health, National Health and Family Planning Commision of the People's Republic of China. His academic interests focus on health policy and rural health.

Qiang Yao (QY) B.S, Ph.D., is a lecturer in the School of Political Science and Public Administration of Wuhan University. His academic interests are in health economics, health policy and systems, health services research and scientometrics.

Ju Sun (JS) M.Ec, Ph.D., is an associate professor and deputy director of the Department of Public Administration Management, School of Political Science and Public Administration of Wuhan University. Her academic interests are in health policy, health economics, health security, social welfare and population health

Zhi-fei He (ZFH) M.Sc, Ph.D., is a candidate in the School of Medicine and Health Management, Tongji Medical College, Huazhong University of Science and Technology. Her academic interests are in health policy and rural health. Lan Yao (LY), M.P.H, Ph.D., is a professor in the School of Medicine and Health Management, Tongji Medical College, Huazhong University of Science and Technology, and executive director of the Chinese Basic Medical Security Research Center, Huazhong University of Science \& Technology. Her academic interests focus on health economics and policy, medical security, community healthcare service, rural healthcare.

Zhi-yong Liu (ZYL), M.S, Ph.D., is an associate professor in the School of Medicine and Health Management, Tongji Medical College, Huazhong University of Science and Technology. His academic interests focus on health service research, hospital information management, health statistics.

\section{Acknowledgments}

We offer our sincere appreciation of the assistance of the Centre for Health Statistics Information, Ministry of Health, People's Republic of China. We also acknowledge the reviewers and editors for their valuable comments.

\section{Funding sources}

There were no external funding sources.

\section{Author details}

${ }^{1}$ School of Medicine and Health Management, Tongji Medical College, Huazhong University of Science and Technology, Wuhan, Hubei 430030,
China. ${ }^{2}$ School of Political Science and Public Administration, Wuhan University, Wuhan, Hubei 430072, People's Republic of China.

Received: 28 April 2015 Accepted: 19 January 2016

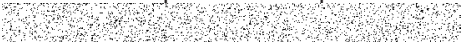

\section{References}

1. National Health and Family Planning Commission of People's Republic of China. China Health Statistics Yearbook 2013. Beijing: Peking Union Medical College Press; 2013.

2. Li L, Chen $\mathrm{Q}$, Powers $\mathrm{D}$. Chinese healthcare reform a shift toward social development. Mod Chin. 2012;38:630-45.

3. Yip WC, Hsiao WC, Chen W, Hu S, Ma J, Maynard A. Early appraisal of China's huge and complex health-care reforms. Lancet. 2012;379:833-42.

4. Around the "Chinese medical reform" of ups and downs in the six inflection point. Oe Weekly (Focus) 2009:20-23.

5. Inventory of Chinese medical reform 30 years (1980-2013). J Med Inform. 2013;34:96

6. Hu R, Shen C, Zou H-f. Health Care System Reform in China: Issues, Challenges and Options. In: China Economics and Management Academy, Central University of Finance and Economics. 2011.

7. Chen Z. Launch of the health-care reform plan in China. Lancet. 2009; 373:1322-4

8. Chang HW, Huang MH. Prominent institutions in international collaboration network in astronomy and astrophysics. Scientometrics. 2013;97:443-60.

9. Zhou P, Zhong YF, Yu MG. A bibliometric investigation on China-UK collaboration in food and agriculture. Scientometrics. 2013;97:267-85.

10. Lee S, Bozeman B. The impact of research collaboration on scientific productivity. Soc Stud Sci. 2005;35:673-702.

11. Hicks D. How much is a collaboration worth? A calibrated bibliometric model. Scientometrics. 1997;40:541-54.

12. Ordonez-Matamoros G. International research collaboration, research team performance, and scientific \& technological capabilities in Colombia-a bottom-up perspective. ProQuest; 2008.

13. Wagner-Döbler R. Continuity and discontinuity of collaboration behaviour since 1800-from a bibliometric point of view. Scientometrics. 2001:52:503-17.

14. Narin F, Whitlow E. Measurement of Scientific Cooperation and Coauthorship in CEC-related Areas of Science (Office for Official Publications of the European Communities, Luxembourg, Report EUR 12900). 1990.

15. Glänzel W. National characteristics in international scientific co-authorship relations. Scientometrics. 2001;51:69-115.

16. Wagner CS, Leydesdorff L. Network structure, self-organization, and the growth of international collaboration in science. Res Policy. 2005; 34:1608-18.

17. Wei H. A bilateral comparison of research performance at an institutional level. Scientometrics. 2015;104:147-73.

18. Yao Q, Lyu PH, Yang LP, Yao L, Liu ZY. Current performance and future trends in health care sciences and services research. Scientometrics. 2014;101:751-79.

19. Yao Q, Lyu PH, Ma FC, Yao L, Zhang SJ. Global informetric perspective studies on translational medical research. BMC Med Inform Decis Mak. 2013;13:77

20. Chen W, Chen S, Qi DC, Gao XY, Wee ATS. Surface transfer p-type doping of epitaxial graphene. J Am Chem Soc. 2007;129:10418-22.

21. Yang L, Chen ZL, Liu T, Wan R, Wang J, Xie WG. Research output analysis of municipal solid waste: a case study of China. Scientometrics. 2013;96:641-50.

22. Stefenon VM, Roesch LFW, Pereira AB. Thirty years of Brazilian research in Antarctica: ups, downs and perspectives. Scientometrics. 2013;95:325-31.

23. Ren JL, Lyu PH, Wu XM, Ma FC, Wang ZZ, Yang G. An informetric profile of water resources management literatures. Water Resour Manag. 2013:27:4679-96

24. Mori $\mathrm{H}$, Nakayama T. Academic Impact of Qualitative Studies in Healthcare: Bibliometric Analysis. Plos One. 2013;8(3):e57371.

25. Diekhoff $\mathrm{T}$, Schlattmann P, Dewey M. Impact of article language in multi-language medical journals - a bibliometric analysis of self-citations and impact factor. Plos One. 2013;8(10):e76816.

26. Bajwa RS, Yaldram K. Bibliometric analysis of biotechnology research in Pakistan. Scientometrics. 2013;95:529-40. 
27. Rosas SR, Kagan JM, Schouten JT, Slack PA, Trochim WMK. Evaluating research and impact: a bibliometric analysis of research by the NIH/NIAID HIV/AIDS clinical trials networks. Plos One. 2011;6(3):e17428.

28. Chen YC, Wu JC, Haschler I, Majeed A, Chen TJ, Wetter T. Academic impact of a public electronic health database: bibliometric analysis of studies using the general practice research database. Plos One. 2011;6(6):e21404.

29. Bajwa RS, Yaldram K, Rafique S. A scientometric assessment of research output in nanoscience and nanotechnology: Pakistan perspective. Scientometrics. 2013;94:333-42.

30. Mahapatra M. On the validity of the theory of exponential growth of scientific literature. In: Proceedings of the 15th IASLIC conference, Bangalore. 1985. p. 61-70.

31. Yao Q, Chen K, Yao L, Lyu PH, Yang TA, Luo F, et al. Scientometric trends and knowledge maps of global health systems research. Health Res Policy Syst. 2014;12:26.

32. Cooper C. Revisiting coauthor responsibility. Science. 2003;299:511.

33. Lucio-Arias D, Leydesdorff L. Main-path analysis and path-dependent transitions in HistCite (TM)-based historiograms. J Am Soc Inf Sci Technol. 2008;59:1948-62.

34. Borgatti SP, Everett MG, Freeman LC. Ucinet for Windows: Software for social network analysis. 2002

35. van Eck NJ, Waltman L. Software survey: VOSviewer, a computer program for bibliometric mapping. Scientometrics. 2010;84:523-38.

36. Ramakrishnan J, Thavamani K. Growth of literature in the field of Hepatitis-C. Libr Philos Pract...2013.

37. Gopalakrishnan S, Natarajan M, Ramesh Babu B. Mapping of nanoscience and nanotechnology research in India: a scientometric analysis, 1990-2009. Scientometrics. 2011:89:501-22

38. Rousseau R. Social network analysis: a powerful strategy, also for the information sciences. J Inf Sci. 2002;28:441.

39. Wu Y, Duan Z. Social network analysis of international scientific collaboration on psychiatry research. Int J Ment Health Syst. 2015;9:2.

40. Bornmann L, Leydesdorff L. Topical connections between the institutions within an organisation (institutional co-authorships, direct citation links and co-citations). Scientometrics. 2015;102:455-63.

41. Han P, Shi J, Li X, Wang D, Shen S, Su X. International collaboration in LIS: global trends and networks at the country and institution level. Scientometrics. 2014;98:53-72.

42. Cao X, Huang $Y$, Wang J, Luan S. Research status and trends in limnology journals: a bibliometric analysis based on $\mathrm{SCl}$ database. Scientometrics. 2012;92:735-46.

43. Garfield E. Citation indexing for studying science. Nature. 1970;227:669-71.

44. Yao Q, Chen J, Lyu PH, Zhang SJ, Ma FC, Fang JG. Knowledge map of artemisinin research in SCl and Medline database. J Vector Borne Dis. 2012; 49:205-16.

45. Li LL, Ding GH, Feng N, Wang MH, Ho YS. Global stem cell research trend: Bibliometric analysis as a tool for mapping of trends from 1991 to 2006. Scientometrics. 2009;80:39-58.

46. Li L, Jiang $Y$, Chen $Q$. A review of China's health care reform after the reform and open policy in 1978. Chin Health Econ. 2008;27:5-9.

47. WHOQOL group. The World Health Organization quality of life assessment (WHOQOL): position paper from the World Health Organization. Soc Sci Med. 1995;41:1403-9.

48. Wu J, Han Y, Zhao FL, Zhou J, Chen Z, Sun H. Validation and comparison of EuroQoL-5 dimension (EQ-5D) and Short Form-6 dimension (SF-6D) among stable angina patients. Health Qual Life Outcomes. 2014;12:156.

49. Chen $Y$, Hicks A, While AE. Quality of life and related factors: a questionnaire survey of older people living alone in Mainland China. Qual Life Res. 2014; 23:1593-602.

50. Li J, Yuan L, Wu Y, Luan Y, Hao Y. The Chinese version of the Pediatric Quality Of Life Inventory (PedsQL) healthcare satisfaction generic module (version 3.0): psychometric evaluation. Health Qual Life Outcomes. 2013;11:113.

51. Cui J, Fang F, Shen F, Song L, Zhou L, Ma X, et al. Quality of Life in Patients With Advanced Cancer at the End of Life as Measured by the McGill Quality of Life Questionnaire: A Survey in China. J Pain Symptom Manage. 2014:48:893-902

52. Wong AH, Tsang HW, Li SM, Fung KM, Chung RC, Leung AY, et al. Development and initial validation of Perceived Rehabilitation Needs Questionnaire for people with schizophrenia. Qual Life Res. 2011;20:447-56.

53. Chou KL, Leung JC. Disability trends in Hong Kong community-dwelling Chinese older adults: 1996, 2000, and 2004. J Aging Health. 2008;20:385-404.
54. Chou KL. The prevalence and clustering of four major lifestyle risk factors in Hong Kong Chinese older adults. J Aging Health. 2008;20:788-803.

55. Liu S, Yam CH, Huang OH, Griffiths SM. Willingness to pay for private primary care services in Hong Kong: are elderly ready to move from the public sector? Health Policy Plan. 2013;28:717-29.

56. Lo RS, Kwan BH, Lau KP, Kwan CW, Lam LM, Woo J. The needs, current knowledge, and attitudes of care staff toward the implementation of palliative care in old age homes. Am J Hosp Palliat Care. 2010;27:266-71.

57. Lau KS, Tse DM, Tsan Chen TW, Lam PT, Lam WM, Chan KS. Comparing noncancer and cancer deaths in Hong Kong: a retrospective review. J Pain Symptom Manage. 2010;40:704-14.

58. Tse DM, Chan KS, Lam WM, Leu K, Lam PT. The impact of palliative care on cancer deaths in Hong Kong: a retrospective study of 494 cancer deaths. Palliat Med. 2007;21:425-33.

59. Yong DS, Kwok AO, Wong DM, Suen MH, Chen WT, Tse DM. Symptom burden and quality of life in end-stage renal disease: a study of 179 patients on dialysis and palliative care. Palliat Med. 2009;23:111-9.

60. Lam TP, Khoo US, Chan YS, Cheng YH, Lam KF. The first batch of graduates of a new medical curriculum in Asia: how their teachers see them. Med Educ. 2004:38:980-6.

61. Lam WW, Fielding R, Johnston JM, Tin KY, Leung GM. Identifying barriers to the adoption of evidence-based medicine practice in clinical clerks: a longitudinal focus group study. Med Educ. 2004;38:987-97.

62. Johnston JM, Leung GM, Fielding R, Tin KY, Ho LM. The development and validation of a knowledge, attitude and behaviour questionnaire to assess undergraduate evidence-based practice teaching and learning. Med Educ 2003:37:992-1000

63. Jin ZC, Wu C, Zhou XH, He J. A modified regression method to test publication bias in meta-analyses with binary outcomes. BMC Med Res Methodol. 2014;14:132.

64. Tang JL, Liu JL. Misleading funnel plot for detection of bias in meta-analysis. J Clin Epidemiol. 2000;53:477-84

65. Foreign-funded project for China rural health [http://www.chinadaily.com. $\mathrm{cn} / \mathrm{m} /$ chinahealth/2014-11/25/content_18975576.htm].

66. Health Policy and Systems Sciences [http://chinamedicalboard.org/ programs/health-policy-and-systems-sciences].

67. The Requirement of Graduate Students' Publications for Doctor's or Master's degrees Application [http://oec.ujs.edu.cn/uploads/cms/201511/ 28/FB28072827988496.pdf].

68. Vinkler P. Correlation between the structure of scientific research, scientometric indicators and GDP in EU and non-EU countries. Scientometrics. 2008;74:237-54

69. Yip W, Hsiao WC. Non-evidence-based policy: how effective is China's new cooperative medical scheme in reducing medical impoverishment? Soc Sci Med. 2009;68:201-9

70. Lei $X$, Lin W. The New Cooperative Medical Scheme in rural China: does more coverage mean more service and better health? Health Econ. 2009;18 Suppl 2:S25-46.

71. Wagstaff A, Lindelow M. Can insurance increase financial risk?: The curious case of health insurance in China. J Health Econ. 2008;27:990-1005.

72. Meng Q, Xu L, Zhang Y, Qian J, Cai M, Xin Y, et al. Trends in access to health services and financial protection in China between 2003 and 2011: a cross-sectional study. Lancet. 2012;379:805-14.

73. Ministry of Health of the People's Republic of China. Report on the implementation of national essential medicines policies. Beijing: Ministry of Health; 2011.

74. Guan $X$, Liang H, Xue Y, Shi L. An analysis of China's national essential medicines policy. J Public Health Policy. 2011;32:305-19.

75. Liu Q, Wang B, Kong Y, Cheng KK. China's primary health-care reform. Lancet. 2011;377:2064-6.

76. Current major project on health care system reform (2009-2011). http://www.gov.cn/test/2009-04/08/content_1280057.htm (published Apr 8, 2009, accessed Dec 8, 2013). [http://www.moh.gov.cn/zwgkzt/ pzcqgh/201204/7d5a2d6f9f2548a4a43652a2e63a7e1e.shtml]

77. Communist Party of China Central Committee: State Council. National Development and Reform Commission Web site. Opinions of the CPC Central Committee and the State Council on deepening the health care system reform, March 17, 2009. 2009.

78. Blumenthal D, Hsiao W. Privatization and its discontents - the evolving Chinese health care system. N Engl J Med. 2005;353:1165-70. 
79. Hu S, Tang S, Liu Y, Zhao Y, Escobar M-L, de Ferranti D. Reform of how health care is paid for in China: challenges and opportunities. Lancet. 2008;372:1846-53.

80. Liu Y, Rao K, Wu J, Gakidou E. China's health system performance. The Lancet. 2008:372:1914-23.

81. Tang S, Meng Q, Chen L, Bekedam H, Evans T, Whitehead M. Tackling the challenges to health equity in China. Lancet. 2008;372:1493-501.

82. Yip W, Hsiao WC. The Chinese health system at a crossroads. Health Affairs. 2008;27:460-8.

83. Yip WC-M, Hsiao W, Meng Q, Chen W, Sun X. Realignment of incentives for health-care providers in China. Lancet. 2010;375:1120-30.

84. Wang L, Kong L, Wu F, Bai Y, Burton R. Preventing chronic diseases in China. Lancet. 2005:366:1821-4.

85. Wang L, Wang Y, Jin S, Wu Z, Chin DP, Koplan JP, et al. Emergence and control of infectious diseases in China. Lancet. 2008:372:1598-605.

86. Yang G, Kong L, Zhao W, Wan X, Zhai Y, Chen LC, et al. Emergence of chronic non-communicable diseases in China. Lancet. 2008;372:1697-705.

87. State Council of People's Republic of China: Opinions of the State Council on deepening the health care system reform main work arrangements in 2012. http://www.gov.cn/zwgk/2012-04/18/content_2115928.htm (published Apr 14, 2012, accessed Dec 8, 2013). 2012.

88. State Council of People's Republic of China: Opinions of the State Counci on deepening the health care system reform main work arrangements in 2013. http://www.moh.gov.cn/tigs/s7846/201307/ e32ef659410449baa79808a00849eb91.shtml (published Jul 18, 2012, accessed Dec 8, 2013). 2013.

89. National Health and Family Planning Commission on the issuance of 2015 points of health planning work [http://www.moh.gov.cn/bgt/s7692/201501/ e804c7cc6e8d4c5d924f4109acc9b45e.shtml].

Submit your next manuscript to BioMed Central and we will help you at every step:

- We accept pre-submission inquiries

- Our selector tool helps you to find the most relevant journal

- We provide round the clock customer support

- Convenient online submission

- Thorough peer review

- Inclusion in PubMed and all major indexing services

- Maximum visibility for your research

Submit your manuscript at www.biomedcentral.com/submit
Biomed Central 